Ethiopian Journal of Environmental Studies \& Management 7(3): 305 - 309, 2014.

ISSN:1998-0507

doi: http://dx.doi.org/10.4314/ejesm.v7i3.10

Submitted: February 11, 2014

Accepted: May 1, 2014

\title{
COMPARISON OF EMPIRICAL MODELS AND LABORATORY SATURATED HYDRAULIC CONDUCTIVITY MEASUREMENTS
}

*PHILIP, H.J., NGALA, A.L. AND WANIYO, U.U.

Department of Soil Science, Faculty of Agriculture, University of Maiduguri, PMB 1069, Maiduguri

\begin{abstract}
Numerous methods for estimating soil saturated hydraulic conductivity exist, which range from direct measurement in the laboratory to models that use only basic soil properties. A study was conducted to compare laboratory saturated hydraulic conductivity $\left(K_{\text {sat }}\right)$ measurement and that estimated from empirical models. Soil samples for the study were collected from four sites at varying depths $(15 \mathrm{~cm}, 30 \mathrm{~cm}, 45 \mathrm{~cm}$ and $60 \mathrm{~cm})$ at the Faculty of Agriculture Teaching and Research Farm, University of Maiduguri. The $K_{\text {sat }}$ value for each sample was determined in the laboratory using the falling head permeameter method. Soil physical properties (bulk density, porosity, gravimetric water content, \% sand and \% silt) required by the models were also determined. A refined Kozeny-Carman model and model developed from multiple regression analysis were used to predict $K_{\text {sat }}$ which were compared with the results obtained from laboratory measurement. The developed model predicted values of $0.0065,0.0010,0.0965$ and $0.0048 \mathrm{~cm} / \mathrm{s}$ at $15 \mathrm{~cm}, 30 \mathrm{~cm}, 45 \mathrm{~cm}$ and $60 \mathrm{~cm}$, respectively, that is closer to the value of $K_{\text {sat }}$ measured in the laboratory $(0.0061,0.0054,0.0050$ and $0.0048 \mathrm{~cm} / \mathrm{s}$ at $15 \mathrm{~cm}, 30 \mathrm{~cm}, 45 \mathrm{~cm}$ and $60 \mathrm{~cm}$, respectively) while Kozeny-Carman model predicted a value of $0.2208,0.2161,0.2020$ and $0.1974 \mathrm{~cm} / \mathrm{s}$ at $15 \mathrm{~cm}, 30 \mathrm{~cm}, 45 \mathrm{~cm}$ and $60 \mathrm{~cm}$, respectively, that is far above the one measured in the laboratory. Therefore, $K_{\text {sat }}$ estimating models could not fit for all locations very well.
\end{abstract}

Key Words: Saturated hydraulic Conductivity, Empirical models, Laboratory measurements

\section{Introduction}

Knowledge of variability of soil physical properties can assist in defining the best strategies for a sustainable soil management through the provision of vital information for estimating soil susceptibility to erosion; hydrological modelling and efficient planning of irrigation projects (Bagarello and Sgroi, 2004). Soil properties such as texture and structure strongly influence water movement within the soil. Saturated hydraulic conductivity depends strongly on soil texture and structure and therefore can vary widely in space. Hydraulic conductivity also shows a temporal variability that depends on different interrelated factors, including soil physical and chemical characteristics affecting aggregate stability, climate, land use, dynamics of plant canopy and roots, tillage operations and activity of soil organisms (Fuentes et al., 2004).

Soil hydraulic conductivity is a measure of soil's ability to transmit water. It is influenced by some soil physical properties and chemical properties and is needed for the study of infiltration, drainage, irrigation and solute movement. Also, it is a key parameter for monitoring of soil and water management (Tayfun, 2005). Knowledge of the rate of water permeability through soil types is essential for determining the type of plants to be grown, plant spacing, yield, managing soil - water systems and erosion control. Compacted soils will have less pore volume resulting in lower hydraulic conductivity especially in clayey soils (Lowery et al., 1996).

Many different techniques have been proposed to determine the value of saturated hydraulic conductivity including field methods (pumping test of wells, auger hole test and tracer test), laboratory methods (constant head and falling head permeameter) and calculations from empirical models (Todd and Mays, 2005). However, accurate estimation of hydraulic conductivity in the field environment by the field methods is limited by the lack of precise knowledge of aquifer geometry and hydraulic boundaries (Uma et al., 1989). The cost of field operations and associated well constructions can be prohibitive. Laboratory tests on the other hand,

*Corresponding Author: Philip, H.J.

Email: hega2014@gmail.com 
presents formidable problems in the sense of obtaining representative samples and very often, long testing times. Alternatively, methods of estimating hydraulic conductivity from empirical models based on grain-size distribution characteristics have been developed and used to overcome these problems (Boadu, 2000). Grain size methods are comparably less expensive and do not depend on the geometry and hydraulic boundaries of the aquifer. Most importantly, the information about the textural properties of soils or rock is more easily obtained.

Hydraulic conductivity can also be estimated by particle size analysis of the sediment of interest using empirical equations relating either hydraulic conductivity to some size property of the sediment (Odong, 2007). Vukovic and Soro (1992) summarised several empirical methods from former studies and presented a general formula:

$$
\mathrm{K}=\frac{g}{v} \cdot \mathrm{C} \cdot \mathrm{f}(\mathrm{n}) \cdot \mathrm{d}_{\mathrm{e}}{ }^{2}
$$

Where $\mathrm{K}$ = hydraulic conductivity, $\mathrm{V}=$ Kinetic viscosity, $\mathrm{g}=$ acceleration due to gravity $\mathrm{C}=$ sorting coefficient $f(n)=$ porosity function and $d_{e}$ $=$ effective grain diameter

The kinematic viscosity (v) is related to dynamic viscosity $(\mu)$ and fluid viscosity $(\rho)$ as follows:

$$
\mathrm{V}=\frac{\mu}{\rho}
$$

The value of $\mathrm{C}, \mathrm{f}(\mathrm{n})$ and $\mathrm{d}_{\mathrm{e}}$ are dependent on the different methods used in the grain-size analysis. According to Vukovic and Soro (1992), porosity (n) may be derived from the empirical relationship with the coefficient of grain uniformity (U) as :

$$
\mathrm{n}=0.255\left(1+0.83^{\mathrm{U}}\right)
$$

Where $U$ is the coefficient of grain uniformity and is given by

$$
\mathrm{U}=\frac{d 60}{d 10}
$$

Here, $d_{60}$ and $d_{10}$ in the formula represent the grain diameter in $(\mathrm{mm})$ for which $60 \%$ and $10 \%$ of the sample respectively are finer than.

$$
\mathrm{K}=\frac{g}{v} \times 6 \times 10^{-4}[1+10(\mathrm{n}-0.26)] \mathrm{d}_{10}{ }^{2} \ldots
$$

Hazen formula was originally developed for the determination of hydraulic conductivity of uniformly graded sand but is also useful for fine sand to gravel range, provided the sediment has a uniformity coefficient less than 5 and effective grain size between 0.1 and $3 \mathrm{~mm}$.

$$
\mathrm{K}=\frac{g}{v} \times 8.3 \times 1
$$

The Kozeny - Carman equation is one of the most widely accepted and used derivations of permeability as a function of the characteristics of the soil medium. This equation was originally proposed by Kozeny (1927) and was later modified by Carman $(1937,1956)$ to become the Kozeny - Carman equation. It is not appropriate for either soil with effective size above $3 \mathrm{~mm}$ or for clayey soils. The main objective of this study is to compare laboratory determined saturated hydraulic conductivity with saturated hydraulic conductivity estimated from empirical models and also to show the relationship between some soil physical properties and saturated hydraulic conductivity.

\section{Materials and Methods Experimental Site}

The soil for the study was collected at the University of Maiduguri Teaching and Research Farm. The site is located in the north eastern part of Nigeria between longitudes $13^{\circ} 05^{\prime \prime} \mathrm{E}$ and latitudes $11^{\circ} 50^{\prime \prime} \mathrm{N}$ and an elevation of $354 \mathrm{~m}$ above sea level. The study area has a tropical climate characterised by low and erratic distribution of rainfall. The mean annual rainfall is about $625 \mathrm{~mm}$ and means annual temperature is between $27-32^{\circ} \mathrm{C}$ (Grema and Hess, 1994). The steady state infiltration varies from $72 \mathrm{~mm}$ $220 \mathrm{~mm} / \mathrm{hr}$ with average of $135 \mathrm{~mm} / \mathrm{hr}$ (Folorunso, 1986). Soil of the study area has a sandy loam textures and has been classified as typic ustipsamment according to USDA system of classification (Rayar, 1983).

\section{Sample Collection and Preparation}

Undisturbed soil samples were collected at $15 \mathrm{~cm}$ depth intervals up to $60 \mathrm{~cm}$ from four sites on the farm using core samplers. The core samples were weighed and immediately oven dried at $105^{\circ} \mathrm{C}$ for 24 hours. After the oven dried soil had been weighed, the bulk density was determined. The duplicated core samples were saturated and used for determination of hydraulic conductivity. Disturbed samples were also collected, air-dried, ground with porcelain pestle and mortar, passed through a $2 \mathrm{~mm}$ sieve and used for the determination of other soil parameters. 


\section{Determination of Soil Physical Properties}

Soil particle size was determined by the hydrometer method (Gee and Bauder, 1979), bulk density was determined using the core sampler method and water content of the soil at the time of sampling was determined in the laboratory by the gravimetric method (Blake, 1965). Saturated hydraulic conductivity was also determined by falling head permeameter method (Klute, 1986).

\section{Regression Models}

Regression equation was developed to predict the $\mathrm{K}_{\mathrm{sat}}$ using some measured physical properties of the soil as descriptor variables. These soil physical properties include bulk density (BD), porosity $(\mathrm{P})$, volumetric water content $(\Theta \mathrm{v})$, percent sand $(\mathrm{Sa})$ and percent silt $(\mathrm{Si})$ from particle size analysis. The regression model relates the $\mathrm{K}_{\text {sat }}$ values to the descriptors via the following equation:

$\mathrm{K}_{\text {sat }}=\mathrm{a}+\mathrm{b}_{1} \mathrm{x}_{1}+\mathrm{b}_{2} \mathrm{x}_{2}+\mathrm{b}_{3} \mathrm{x}_{3}+\mathrm{b}_{4} \mathrm{x}_{4}+\mathrm{b}_{5} \mathrm{x}_{5}$

Where $\mathrm{K}_{\text {sat }}=$ saturated hydraulic conductivity

$\mathrm{a}=$ constant

$b_{1}-b_{5}=$ coefficients determined by

regression analysis

$$
\begin{aligned}
& \mathrm{x}_{1}=\text { Bulk Density } \\
& \mathrm{x}_{2}=\text { Porosity } \\
& \mathrm{x}_{3}=\text { Volumetric water content } \\
& \mathrm{x}_{4}=\% \text { sand } \\
& \mathrm{x}_{5}=\% \text { silt }
\end{aligned}
$$

The resulting regression equation that best relates $\mathrm{K}_{\text {sat }}$ to the five descriptors of soil properties is given as:

$\mathrm{K}_{\mathrm{sat}}=0.07118-0.03266 \mathrm{BD}-0.00077 \mathrm{P}+$ $0.39201 \Theta_{v}+0.00121 \mathrm{Sa}+0.0002572 \mathrm{Si}$

The above equation describes a model that predicts $\mathrm{K}_{\text {sat }}$ of a soil using information from soil parameters as bulk density, porosity, water content, percent sand and percent silt.

\section{Statistical Analysis}

Experimental data were analysed using descriptive statistics, correlation and multiple regression using Statistix9, statistical software package (Microsoft, 2009).

\section{Results and Discussion}

Some Selected Soil Properties of the Study Area

The descriptive statistics on \%sand, \%clay and \%silt, bulk density $\left(\mathrm{g} / \mathrm{cm}^{3}\right)$, volumetric water content $\left(\mathrm{cm}^{3} / \mathrm{cm}^{3}\right)$, porosity $(\%)$ and $\mathrm{K}_{\mathrm{sat}}(\mathrm{cm} / \mathrm{s})$ is shown in Table 1 . The range values of $\%$ sand are $66.9-69.4 \%$, \%silt is $6.6-14.1 \%$ and \%clay is $19.0-24.0 \%$. Hence the textural class of the soil of the study area is described as sandy loam using Marshall's Textural Triangle. The bulk density ranges from $1.46-1.62 \mathrm{~g} / \mathrm{cm}^{3}$, porosity ranges from $39-45 \%$ and water content ranges from $0.0149-0.0153 \mathrm{~cm}^{3} / \mathrm{cm}^{3}$

\section{Correlation coefficient of Some Soil Properties}

The results on the correlation coefficients on selected soil properties and the saturated hydraulic conductivity are given in Table 2. Clay content showed significantly negative correlation with the saturated hydraulic conductivity $(\mathrm{P}<$ $0.01)$. This agrees with the findings of Tayfum (2005) who reported significant negative correlation of clay content with soil $\mathrm{K}_{\text {sat }}$ that, as clay content increases, $\mathrm{K}_{\text {sat }}$ decreases and vice versa. Also, there is a high negative correlation between bulk density and porosity at $\mathrm{P}<0.01$, implying that increase in bulk density will cause a decrease in pore spaces of the soil. This agrees with the findings of Edoga (2010) who reported negative correlation between bulk density and porosity.

There is a significant negative correlation at $\mathrm{P}<0.01$ between porosity and clay content. This means that increase in clay content reduces the soil pore spaces hence the ability of the soil to transmit water is also affected. There is a positive correlation between bulk density and silt and clay contents at $(\mathrm{P}<0.05)$. Increase in clay and silt contents will cause a resultant increase in bulk density thus affecting saturated hydraulic conductivity.

Bulk density and porosity also showed significant negative correlation with the $\mathrm{K}_{\text {sat }}$ at $\mathrm{P}<0.01$. Thus, the higher the bulk density, the lower the ability of the soil to transmit water, the less the number of macro pores. High bulk density decreases the number of macro pores in the soil thereby making it difficult for water to move through the soil. This agrees with the findings of Edoga (2010) who reported that bulk density and clay content has an impact on $\mathrm{K}_{\text {sat }}$, and that as clay content and bulk density increases, saturated hydraulic conductivity decreases. It shows that clay content, bulk density 
and porosity were the most important soil properties affecting $\mathrm{K}_{\mathrm{sat}}$

\section{Comparison between Laboratory Measurement and Empirical Measurement on $K_{\text {sat }}$}

Table 3 shows the comparison between $\mathrm{K}_{\text {sat }}$ measured in the laboratory using falling head permeameter method and $\mathrm{K}_{\mathrm{sat}}$ estimated from two empirical models (Kozeny-Carman and model developed from multiple regression analysis). The table showed that model developed from multiple regression analysis predicted a closer value of $\mathrm{K}_{\mathrm{sat}}$ as the one measured in the laboratory, while Kozeny-Carman model predicted a $\mathrm{K}_{\mathrm{sat}}$ value that is far greater than the one measured in the laboratory. This suggests that Kozeny-Carman equation might not be suitable for predicting the $\mathrm{K}_{\text {sat }}$ of the study area probably due to difference in climatic and ecological zone. Similar study was carried out in Samaru, Zaria by Edoga (2010) comparing $\mathrm{K}_{\text {sat }}$ measurement methods with some empirical models as Yannopoulos equation and KozenyCarman equation.His results showed that Kozeny-Carman equation is not suitable for the ecological zone but Yannopoulos equation predicted a value of $\mathrm{K}_{\text {Sat }}$ that is closer to the one measured in the laboratory.

\section{Conclusion}

The results of this study showed that KozenyCarman equation might not be suitable for the soils of the study area despite its wide usage for predicting $\mathrm{K}_{\mathrm{sat}}$, while the model developed from multiple regression analysis with $\mathrm{R}^{2}=92 \%$ is best fitted for the soils of the study area. The presented regression model is suggested as useful alternative to laboratory analysis especially for soils that may be difficult to prepare for measurements or may take several days or perhaps weeks for $\mathrm{K}_{\mathrm{sat}}$ measurements. In certain circumstances, the model may also be useful in giving first hand information about hydraulic properties in a field environment.

\section{References}

Bagarello, V. and Sagrroi, A. (2004). Using the single-ring Infiltrometer method to Detect

Temporal changes in surface soil field saturated hydraulic conductivity. Soil Tillage Research 76: 13 - 24 .
Blake, G.R. and Hartge, K.H. (1986). Bulk Density. Methods of Soil Analysis Part 1. Soil Science Society of America, pp 363 376, Madison, WI, USA.

Boadu, F.K. (2000). Hydraulic Conductivity of Soils from Grain - Size Distribution: New Models. Journal of Geotechnical and Geoenvironmental Engineering.

Carman, P.C. (1937). Fluid flow through granular beds. Trans. Inst. Chemical Eng. 15:150.

Carman, P.C. (1956). Flow of Gases Through Porous Media. Butterworths Scientific Publications. London.

Edoga, R.N. (2010). Comparison of Saturated Hydraulic Conductivity Measurement Methods for Samaru-Nigeria Soils. Libyan Agriculture Research Centre Journal International 1(4): 269 - 273.

Fuentes, J.P., Flury, M., Bezdicek, D.F. (2004). Hydraulic Properties in a silt Loam soil Under Natural Praire, Conventional Tillage and No-Till. Soil Sci. Soc. America Journal 68: $1679-1688$.

Gee, G.W. and Bauder, J.W. (1979). Particle Size Analysis by Hydrometer: A Simplified Method for Routine Textural Analysis and a Sensitivity Test of Measured Parameters. Soil Sci. Soc. Am. J., 43: 1004 - 1007.

Kozeny, J. (1927). Uber Kapillare Leitung Des Wassers in Boden. Sitzungsber Akad. Wiss. Wien Math. Naturwiss. KI., Abt. 2a, 136: 271 - 306 (In German).

Lowery, B., Arshad, M.A., Lal, R., Hickey, W.J., (1996). Soil Water Parameters and SoilQuality. In: Doran, J. W and Jones, A. J. (eds) Methods for Assessing Soil Quality Soil Sci. Soc. Am. Spec. Publication 49. SSSA.

Odong, J. (2007). Evaluation of Empirical Formulae for Determination of Hydraulic Conductivity based on Grain-Size Analysis. J. Am. Sci, 3(3): $54-60$.

Tayfun, A. (2005). Saturated Hydraulic Conductivity: A Study of Path Analysis in Clayey Soils Ataturk University Ziraat Fak. Derg 36(1): $23-25$.

Todd, D.K. and Mays, L.W. (2005). Groundwater Hydrology. John Wiley \& Sons, New York.

Uma, K.O., Egboka, B.C.E.R. and Onuoha, K.M. (1989). New Statistical Grain Size Method 
for Evaluating the Hydraulic Conductivity of Sandy Aquifers. J. Hydrol., 108: 143 366.
Vukovic, M., and Soro, A. 1992. Determination of Hydraulic Conductivity of Porous Media From Grain Size Analysis Composition. Water Resources Publications, Littleton, Colorado.

Table 1: Descriptive Statistics on Some Selected Soil Properties

\begin{tabular}{llllll}
\hline Soil Property & Min. & Max. & Mean & SE & SD \\
\hline Sand $(\%)$ & 66.900 & 69.400 & 67.681 & 0.299 & 1.197 \\
Silt $(\%)$ & 6.600 & 14.100 & 11.131 & 0.521 & 2.085 \\
Clay $(\%)$ & 19.000 & 24.000 & 21.19 & 0.459 & 1.797 \\
BD $\left(\mathrm{gcm}^{3}\right)$ & 1.460 & 1.620 & 1.54 & 0.015 & 0.059 \\
Porosity $(\%)$ & 39.000 & 45.00 & 14.750 & 0.544 & 2.176 \\
$\Theta_{\mathrm{v}}\left(\mathrm{cm}^{3} / \mathrm{cm}^{3}\right)$ & 0.0149 & 0.0153 & 0.015 & 0.00003 & 0.00011 \\
$\mathrm{~K}_{\mathrm{sat}}(\mathrm{cm} / \mathrm{s})$ & 0.0045 & 0.0066 & 0.0055 & 0.00018 & 0.00070 \\
\hline
\end{tabular}

Table 2: Correlation Coefficients on Some Selected Soil Properties

\begin{tabular}{lllllll}
\hline & $\mathrm{K}_{\mathrm{sat}}$ & $\mathrm{BD}$ & Porosity & $\Theta \mathrm{v}$ & Sand & Silt \\
\hline BD & $-0.8829^{* *}$ & & & & & \\
Porosity & $0.8609^{* *}$ & $-0.9931^{* *}$ & & & & \\
$\Theta_{\mathrm{v}}$ & -0.1852 & 0.3181 & -0.3713 & & & \\
Sand & -0.1246 & 0.1949 & -0.2400 & 0.2308 & & \\
Silt & $0.8062^{*}$ & $0.7831^{*}$ & $0.8173^{*}$ & -0.4157 & -0.5113 & $-0.8200^{*}$ \\
Clay & $-0.8527^{*}$ & $0.7790^{*}$ & $-0.7887^{*}$ & 0.3287 & 0.0727 & \\
\hline
\end{tabular}

*Significant at $\mathrm{P}<0.05$, ** significant at $\mathrm{P}<0.01$

Table 3: $\mathrm{K}_{\text {sat }}$ measured in laboratory and prediction from the two models at various depths

\begin{tabular}{llll}
\hline Depth & $\mathrm{K}_{\text {sat }}(\mathrm{cm} / \mathrm{s})$ & & \\
\hline & Kozeny-Carman & Regression Model & Laboratory \\
$15 \mathrm{~cm}$ & 0.2208 & 0.0065 & 0.0061 \\
$30 \mathrm{~cm}$ & 0.2161 & 0.0060 & 0.0054 \\
$45 \mathrm{~cm}$ & 0.2020 & 0.0065 & 0.0050 \\
$60 \mathrm{~cm}$ & 0.1974 & 0.0048 & 0.0048 \\
\hline
\end{tabular}

